$\begin{gathered}\text { EPiC Series in Education Science } \\ \text { Volume 1, 2017, Pages 402-410 }\end{gathered}$
$\begin{gathered}\text { AUBEA 2017: Australasian Universities Build- } \\ \text { ing Education Association Conference 2017 }\end{gathered}$

\title{
A Framework for Successful Implementation of Green Supply Chain Management (GSCM) in Construction Organisations
}

\author{
Ankita Wyawahare ${ }^{1 *}$ and Nilupa Udawatta ${ }^{1 \dagger}$ \\ Deakin University, Australia \\ awyawah@deakin.edu.au, nilupa.udawatta@deakin.edu.au
}

\begin{abstract}
Green Supply Chain Management (GSCM) is considered as one of the main efforts, which aim to integrate environmental parameters within the supply chain management. It helps to reduce carbon emissions and improve environmental performances of organisations. As a result of that GSCM has been integrated into the strategic planning of most of the construction organisations. As in case of all radical innovations, barriers or challenges are also expected to be present in the implementation process of GSCM in construction organisations. Hence, it is essential for organisations to identify any barriers that they may face and establish approaches for successful implementation of GSCM in their organisations. Thus, this research aims to develop a conceptual framework by conducting a comprehensive literature review on GSCM practices to address the above-mentioned issues. According to the research findings, the main barriers to implementing GSCM can be categorised into five main categories such as technology, knowledge, finances, outsourcing and management. Furthermore, the strategies to improve GSCM practices in construction organisations include: commitment of top management; changes in existing policies and technologies; improve the awareness of environmental issues; training and education; and implementation of efficient materials and waste management systems. The suggested framework can be applied in construction organisations to identify the key components of GSCM and self-assessment of barriers and strategies to successfully implement GSCM in construction organisations.
\end{abstract}

Keywords: Barriers, Construction Organisations, Green Supply Chain Management (GSCM), Strategies

*Prepared as a requirement of Masters Degree

$\dagger$ Supervised and edited the student's work 


\section{Introduction}

The construction industry practices are criticised due to its negative impacts on the environment such as high energy usage, greenhouse gas emission and waste generation (Deshpande, 2012; Kim, Woo, Rho, \& Chung, 2016; Selvaraj, 2012). Thus, it is necessary to reduce the negative impacts of construction activities on the environment reconsidering its traditional supply chain management (SCM) practices. Thus, green supply chain management (GSCM) can be identified as one of the solutions to resolve the above mentioned issues (Gandhi, Mangla, P. Kumar, \& D. Kumar, 2015). Green supply chain management is defined as incorporation of "environmental thinking into SCM, including product design, material sourcing and selection, manufacturing practices, delivery of the final products to the consumers, and end-of-life management of the product after its intended life" (Tyagi, P. Kumar, \& D. Kumar, 2008). As a result of increase in competitive and marketing demands and regulatory pressures for environmental concerns, organisations tend to integrate green practices in their work practices (Baresel-Bofinger \& Ketikidis, 2010). In the process of all radical innovations, barriers or challenges are also expected to be present. Thus, the aim of this research is to develop a conceptual framework for successful implementation of GSCM practices in construction organisations. In order to achieve the above mentioned aim, a comprehensive literature review was conducted focusing on GSCM practices, barriers to implementing GSCM and strategies for successful implementation of GSCM in construction organisations.

\section{Literature Review}

The rapid development in the construction industry causes negative impacts on the environmental due to high resource consumption, environmental pollution and waste generation (Wong, Lai, Lun, \& Cheng, 2015). Green supply chain management (GSCM) is one of the best strategies to overcome these challenges as it improves the environmental performance of organisations (Balasubramanian, 2012; Minsqiang and Zou, 2011). However, irrespective of the growing awareness, not all construction organisations have successfully implemented GSCM practices due to presence of various barriers in the implementation process (Meythi and Martusa, 2013). Thus, the evolution of SCM into GSCM requires strong commitment from the organisations and related government and other agencies (Jaggernath and Khan, 2015).

\subsection{Supply Chain Management and Green Supply Chain Management}

The concept of SCM was developed in 1970's by focusing on outsourcing, assembling and delivery of products to clients (Mentzer, DeWitt, Keebler, Min, Nix, Smith, \& Zacharia, 2001). The Global Supply Chain Forum defines SCM as "the integration of key business processes from end users through original suppliers that provide products, services, and information that add value for customers and other stakeholders" (Lambert, Cooper, \& Pagh, 1998). Later on the concept of GSCM has developed by integrating environmentally friendly practices to SCM practices (Jaggernath and Khan, 2015; Sarkis, Zhu, \& Lai, 2011).

Implementation of GSCM practices has become important part of organisations and GSCM turns into a major and important strategical drive for business organisations. According to Hervani, Helms, \& Sarkis (2005), GSCM comprises green manufacturing, green purchasing, green management, green marketing/ distribution and reverse logistics. 


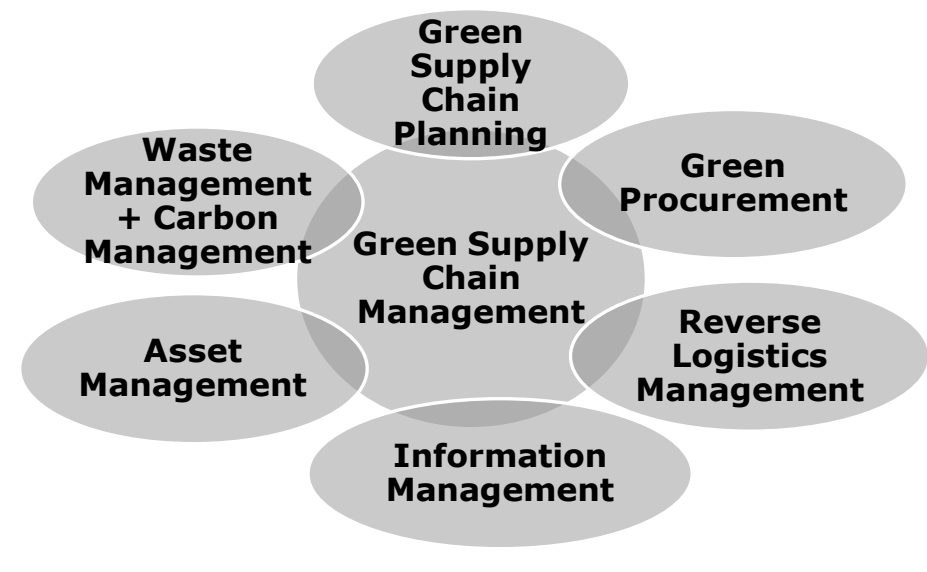

FIGURE 1: Components of Green Supply Chain Management

As shown in the above figure, GSCM comprises of green material management and planning, green procurement, green marketing, and reverse logistics. Gandhi et al. (2015) stated that competitive advantages of construction companies can be improved by implementing green practices. Similarly, it helps to minimise waste generation, maximise environmental performance, improve costeffectiveness and improve organisational skills. Therefore, implementation of GSCM plays vital role in organisations at both environmental and organisational levels (Gandhi et al., 2015). As construction is a project based industry, special capabilities are required when implementing GSCM by considering design, procurement, manufacturing, engineering and logistics needs of construction projects.

\subsection{Implementation GSCM in Construction Organisations at Different Stages}

Implementation of GSCM in organisations is relatively differed from traditional SCM (Elbarkouky and Abdelazeem, 2013). According to Sarkis (2003), the transition stages of traditional SCM to GSCM implementation include: product lifecycle; operational lifecycle; and waste minimisation. 


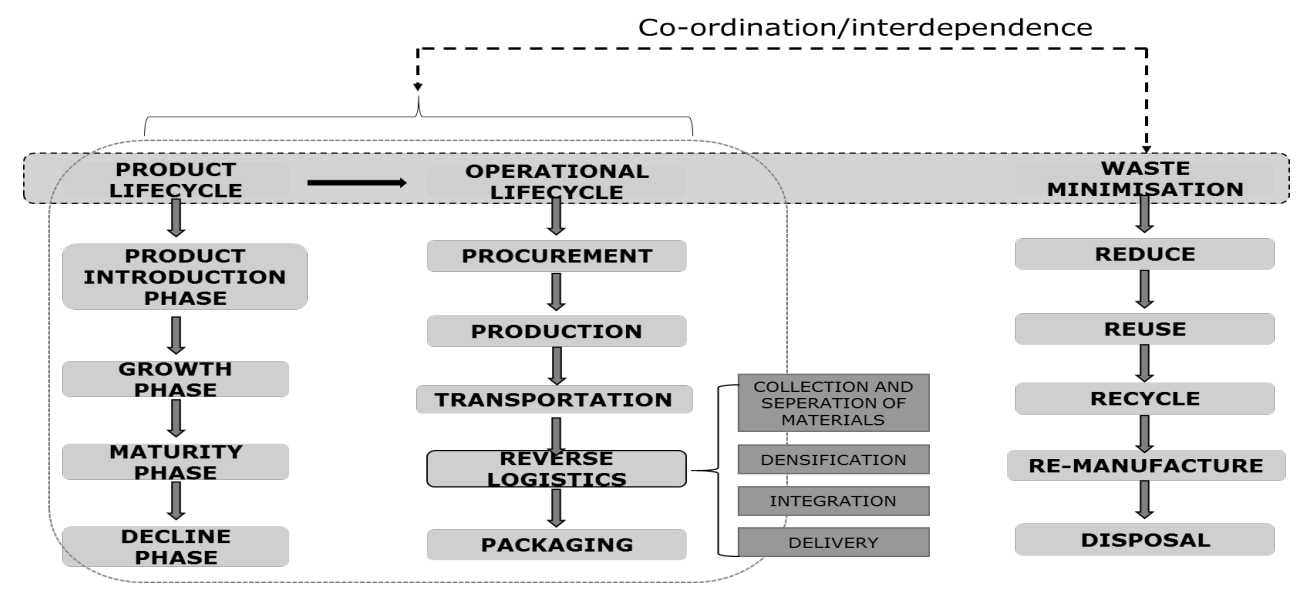

FIGURE 2: The key transition stages from traditional SCM to GSCM

The product life cycle phase comprises of four phases including product introduction, growth, maturity and decline (Sarkis, 2003). The product introduction phase is the actual design phase. Thus, the impact of the design should be taken into the consideration with respect to energy consumption, material selection and reverse logistics in the manufacturing process along with designing products to be recyclable, remanufactured and repaired (Dube and Gawande, 2011). Similarly, the growth phase facilitates recycling and remanufacturing of the products considering reverse logistics (Dube and Gawande, 2011). Sarkis (2003) highlighted that in order to be environmentally efficient, reverse logistics and improved processes need to be considered in maturity and decline phases of product lifecycle.

The operational life cycle phase includes procurement, production, transportation, reverse logistics and packaging. Dube and Gawande, (2011) define green procurement as "the integration of environmental considerations into purchasing programs, policies and actions". Furthermore, Sarkis (2003) highlighted that organisations should be willing to purchase reusable and recyclable materials from suppliers who have ISO 14000 certifications. Similarly, evaluation of environmental performance should be included in the criteria of contract award along with considerations of cost and quality of performances. Transportation and distribution are important factors in the operational life cycle phase (Elbarkouky and Abdelazeem, 2013). Locations of distribution outlets should be considered in the successful implementation of GSCM in construction organisations to reduce transportation costs, fuel expenses and to reduce pollution from vehicles (Sarkis, 2003). Environmental reverse logistics can be defined as "the return into forward supply chain of reusable and recyclable materials and products" (Sarkis, 2003). Reverse logistics namely considers of four stages: collection and separation of materials transitional processing; densification; integration; and delivery. These stages may differ depending on industry types, product types, clients and organisations requirements (Elbarkouky and Abdelazeem, 2013; Sarkis, 2003). Conservation of natural resources and cost reduction are two major benefits of reverse logistics. Green packaging is one of the other consideration in GSCM and it helps to reduce material usage, better space utilisation in storage and reduce amount of resources and tools required in construction activities (Dube and Gawande, 2011).

The last key elemental stage is waste management. This stage can be further sub-categorised into five different stages: reuse; reduce; recycle; disposal; and remanufacture. Total quality management (TQM) and just in time program can help achieve efficient waste reduction practices as well 
(Elbarkouky and Abdelazeem, 2013). The remaining four processes recycle, reuse, disposal and remanufacture can be termed as end of the pipeline practices (Sarkis, 2003).

\subsection{Barriers to Implementing GSCM in Construction Organisations}

Integration of GSCM into traditional SCM demands careful analysis and systematic changes in existing systems (Balasubramanian, 2012). Companies should be well equipped to mitigate any barriers, which may affect the working of an organisation internally as well as externally. Although it is not possible to mitigate all the barriers simultaneously, a careful analysis of these barriers can help to prioritise them and achieve successful implementation of GSCM (Deepak, Haq, \& Mathiyazhagan, 2014). The external barriers in successful implementation of GSCM in construction organisations are rigid practices of suppliers, lack of data availability to measure GSCM performance, financial constraints and changing regulations. Internal barriers include the novelty of GSCM, lack of support from top management and lack of communications (Deepak et al., 2014). Other common barriers include lack of public awareness (Zhang, Bi, \& Liu, 2009), lack of government support for adoption of new techniques (Dube and Gawande, 2011), lack of involvement of top management and lack of transition from traditional to modern techniques. Furthermore, financial constraints (Govindan et al., 2014), lack of organisations mission and vision towards sustainable practices (Deepak et al., 2014), poor knowledge (Parmar, 2016) and communication management techniques (Dashore and Sohani, 2013) were also noted as common barriers. In construction organisations, environmental issues have become more relevant, where organisations need to focus on efficient energy and resource utilisation for environmentally sustainable supply chain. From analysing the barriers and their sources for successful implementation of GSCM, no individual stream acts as the only barrier and that they are inter-dependent on each other.

\subsection{Strategies for Successful Implementation of GSCM in Construction Organisations}

Strategies for successful implementation of GSCM include identification of relevant goals and long term planning for managing and achieving these identified goals (Mudgal et al., 2009). The selection of the most suitable strategy also depends on regulations, government policies and customer's awareness (Hsu and $\mathrm{Hu}, 2008$ ). Thus, environmental friendly policies and subsidiaries are vital in the implementation process of GSCM in construction organisations (Balasubramanian, 2012). Trained professionals with appropriate knowledge of GSCM is important to achieve desired results and overcome the barriers of implementation of GSCM in construction organisations (Kamolkittiwong and Phruksaphanrat, 2015). Awareness of professionals, suppliers and end users about GSCM also helps to successful implementation of GSCM in construction organisations (Ibrahim, et al., 2010). Barriers such as lack of knowledge regarding reverse logistics and ineffective designs regarding reuse or recycle can be mitigated by effective reverse logistics management (Govindan, Kaliyan, Kannan, \& Haq, 2014).

\section{Proposed Conceptual Framework}

Green Supply Chain Management (GSCM) has emerged as a crucial organisational philosophy with aims for reducing risks related to environment and having a sustainable future (Dashore and Sohani, 2013). The proper identification of barriers strategies of implementing GSCM can be useful for successful implementation of GSCM in construction organisations. As highlighted in the literature review, GSCM helps to improve the economic and environmental performance of organisations at 
different levels, as it contains green procurement, green manufacturing, carbon and waste management, reverse logistics and financial management (Gandhi et al., 2015). Similarly, it is necessary to carefully evaluate the key elemental stages involved in implementation of SCM such as product lifecycle, operational lifecycle and waste minimisation. The effective reverse logistics management plays a crucial role in GSCM as it facilitates products recycling, reusability and remanufacturing (Sarkis, 2003).

However, there are numerous barriers to implementing GSCM in construction organisations such as lack of government support, lack of support from top management, financial constraints and lack of public awareness. The strategies for implementing GSCM include: government subsidiaries; commitment of top management; effective reverse logistics management; efficient financial management; increasing public awareness about environmental concerns and efficient waste management and reusability techniques. The figure 3 portrays flow chart with three major sections by noting six main components of GSCM, barriers related to each component and strategies to mitigate those barriers. The suggested framework will help future employers, designers, manufacturers, contractors, suppliers, end-users and existing construction organisations as well during adoption and implementation of GSCM. 


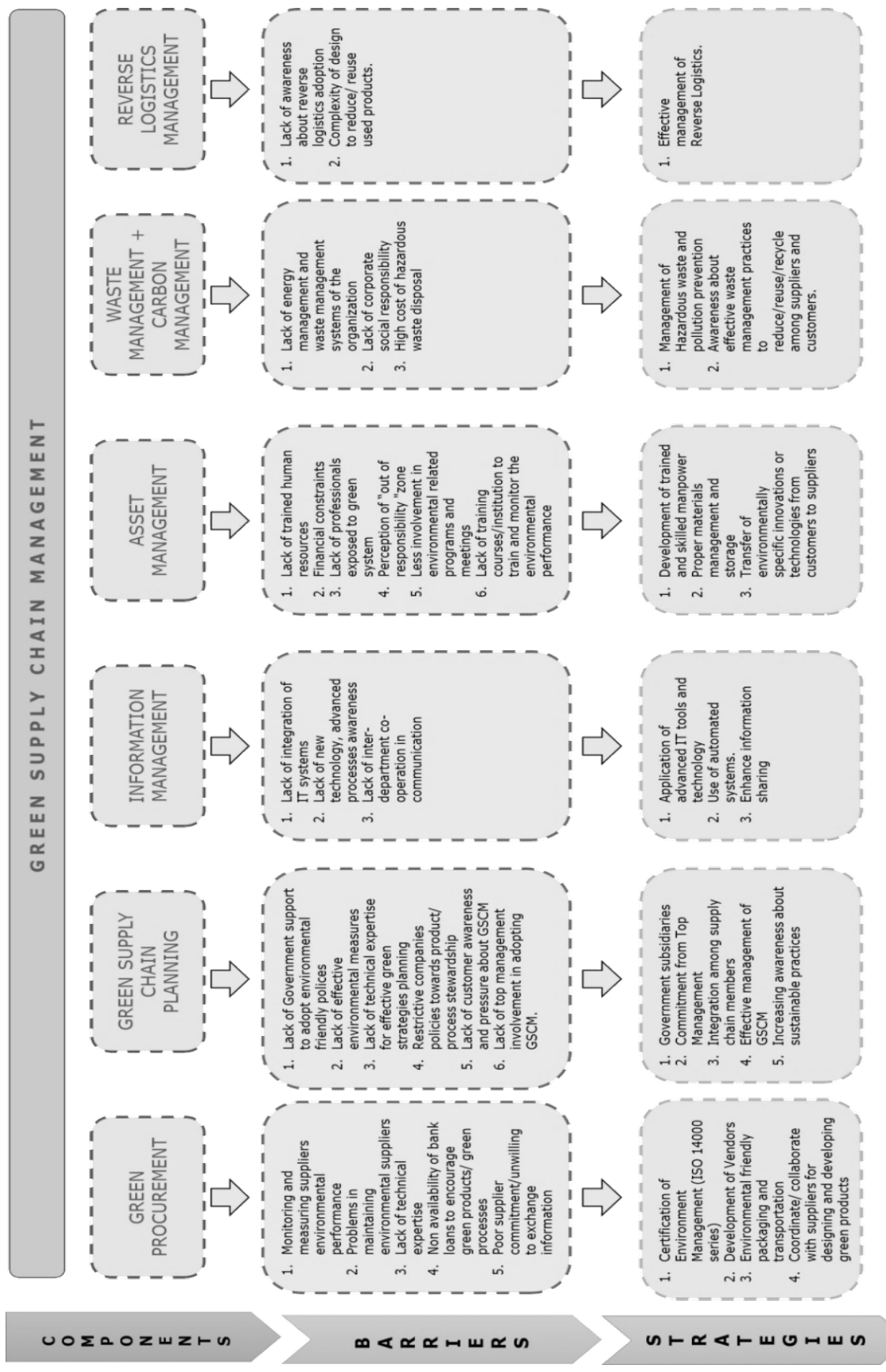

FIGURE 3: The proposed conceptual framework 


\section{Conclusions}

This research study provided an insight to the implementation of GSCM in construction organisations. The critical analysis of existing literature highlighting a gap in the knowledge in relation to awareness of GSCM and its adoption in construction organisations. Thus, in this research a conceptual framework was developed to enable successful implementation of GSCM in construction organisations. The main barriers to implementing GSCM can be identified as technology, knowledge, finances, outsourcing and management. The strategies to improve GSCM practices in construction organisations include: commitment of top management; changes in existing policies and technologies; improve the awareness of environmental issues; training and education; and implementation of efficient materials and waste management systems. This suggested framework can be useful for construction practitioners to successfully implement GSCM in their organisations.

\section{References}

Balasubramanian, S. (2012). A hierarchical framework of barriers to green supply chain management in the construction sector. Journal of Sustainable Development, 5(10), 15-27.

Baresel-Bofinger, A.C. \& Ketikidis, P.H. (2010). Using 'green knowledge' for implementing environmental supply chain management practices in Greek manufacturers. Paper presented at 5 th International Forum on Knowledge Asset Dynamics (IFKAD 2010), Madrid, Italy.

Dashore, K. \& Sohani, N. (2013). Green supply chain management- barriers and drivers: a review. International Journal of Engineering Research and Technology, 2(4), 2021-2030.

Deepak, M., Haq, A.N. \& Mathiyazhagan, K. (2014, December). Identification of pressures, barriers and drivers for the implementation of green supply chain management, Paper presented at the 5th International \& 26th All India Manufacturing Technology, Design and Research Conference (AIMTDR 2014), Assam, India.

Deshpande, A.R. (2012). Supply chain management dimensions, supply chain performance and organizational performance: an integrated framework. International Journal of Business and Management, 7 (8), 2-19.

Dube, A. S. \& Gawande, R. R. (2011). Green supply chain management - a literature review. International Journal of Computer Applications (0975-8887).

Elbarkouky, M. M. G. \& Abdelazeem, G. (2013). A green supply chain assessment for construction projects in developing countries. WIT Transactions on Ecology and the Environment, 2 (8), 1331-1341.

Gandhi, S., Mangla, S.K., Kumar, P. \& Kumar, D. (2015). Evaluating factors in implementation of successful green supply chain management using DEMATEL: A case study. International Strategic Management Review, 3 (1-2), 96-109.

Govindan, K., Kaliyan, M., Kannan, D. \& Haq, A.N. (2014). Barriers analysis for green supply chain management implementation in Indian industries using analytic hierarchy process. International Journal of Production Economics, 147, 555-568.

Hervani, A.A., Helms, M.M. \& Sarkis, J. (2005). Performance measurement for green supply chain management. Benchmarking: An International Journal, 12(4), 330-353.

Hsu, C. W. \& Hu, A. H. (2008). Green Supply Chain Management in the Electronic Industry. International Journal of Science and Technology, 5(2), 205-216. 
Ibrahim, A. R. B., Roy, M. H., Ahmed, Z. \& Imtiaz, G. (2010). An investigation of the status of the Malaysian construction industry. Benchmarking: An International Journal, 17 (22), 294308.

Jaggernath, R. \& Khan, Z. (2015). Green supply chain management. World Journal of Entrepreneurship Management and Sustainable Development, 11 (1), $37-47$.

Kamolkittiwong, A. \& Phruksaphanrat, B. (2015). An analysis of drivers affecting green supply chain management implementation in electronics industry in Thailand. Journal of Economics, Business and Management, 3 (9), 864-869.

Kim, M.G., Woo, C., Rho, J.J. \& Chung, Y. (2016). Environmental capabilities of suppliers for green supply chain management in construction projects: a case study in Korea. Sustainability, $8(1), 82$.

Lambert, D.M., Cooper, M.C. \& Pagh, J.D. (1998). Supply chain management: implementation issues and research opportunities. The International Journal of Logistics Management, 9 (2), 1-20.

Mentzer, J.T., DeWitt, W., Keebler, J.S., Min, S., Nix, N.W., Smith, C.D. \& Zacharia, Z.G., 2001. Defining supply chain management. Journal of Business Logistics, 22(2), 1-25.

Meythi \& Martusa, R. (2013). Green supply chain management: strategy to gain competitive advantage. Journal of Energy Technologies and Policy, 3 (11), 334-341.

Minsqiang, Z. \& Zou, Z. (2011). Green Supply Chain Management in Construction Industry. Innovative Computing and Information, 81-86.

Mudgal, R.K., Shankar, R., Talib, P. \& Raj, T. (2009). Greening the supply chain practices: an Indian perspective of enablers' relationship. International Journal of Advanced Operations Management, 1, 151-176.

Parmar, N. K. (2016). Analysis of Barriers for implementing green supply chain management in small and medium sized enterprises of India. International Journal of Humanities and Management Sciences, 4(3).

Sarkis, J. (2003). A strategic decision framework for green supply chain management. Journal of Cleaner Production, 11, 397- 409.

Sarkis, J., Zhu, Q. \& Lai, K.H. (2011). An organizational theoretic review of green supply chain management literature. International Journal of Production Economics, 130(1), 1-15.

Selvaraj, R. K. (2012). A Study on the Implementation of Green Supply Chain- A Comparative Analysis between Small Scale Industries in India and Developed Nations, Mälardalen University.

Tyagi, M., Kumar, P. \& Kumar, D. (2008). Assessment of critical enablers for flexible supply chain performance measurement system using fuzzy DEMATEL approach. Global Journal of Flexible Systems Management, 16(2), 1-18.

Wong, C. W., Lai, K. H., Lun, Y. H. \& Cheng, T. E. (2015). Environmental management: the supply chain perspective, Springer.

Zhang, B., Bi, J. \& Liu, B. (2009). Drivers and barriers to engage enterprises in environmental management initiatives in Suzhou Industrial Park, China. Frontiers of Environmental Science \& Engineering in China, 3(2), 210-220. 